\title{
Housing Space Quality towards Quality Of Life: A Case Study of Double Storey Terrace Houses
}

\author{
Aniza Abu Bakar ${ }^{a}, 1$,Nurhayati Abdul Malek ${ }^{\mathrm{b}}$, Mohamad Abdul Mohit ${ }^{\mathrm{c}}$, Rosniza Othman ${ }^{\mathrm{d}}$, and Aliyah Nur Zafirah Sanusi ${ }^{\mathrm{d}}$ \\ aDept. of Landscape Architecture, Kulliyyah of Architecture and Environmental Design, International Islamic University Malaysia, Jalan \\ Gombak, 53100 Kuala Lumpur, Malaysia \\ ${ }^{b}$ Dept. of Landscape Architecture, Faculty of Architecture, Planning and Surveying, UiTM, Puncak Alam, 42300 Selangor, Malaysia \\ 'Dept. of Urban and Regional Planning, Kulliyyah of Architecture and Environmental Design, International Islamic University Malaysia, \\ Jalan Gombak, 53100 Kuala Lumpur, Malaysia \\ ${ }^{d}$ Dept. of Architecture, Kulliyyah of Architecture and Environmental Design, International Islamic University Malaysia, Jalan Gombak, \\ 53100 Kuala Lumpur, Malaysia \\ aaniza@iium.edu.my, nurhayati.abdmalek@gmail.com, mamohit@iium.edu.my, rosniza@iium.edu.my, aliyah@iium.edu.my
}

\begin{abstract}
The success of every housing area is determined by its user satisfaction level, living there. The quality of the house, its spaces within the unit, housing neighbourhood and green open space can directly influence the quality of life. Limitation of space following high land cost in an urban area, evaluation of the housing environment as a whole including the green open space needs to be studied as it affects the residents' satisfaction level. This study concentrates on spaces within a housing area to evaluate the residents' level of satisfaction of the Taman Melati Mastika (TMM), Kuala Lumpur and to understand how they perceived their quality of life through the housing environment and the availability of green open space. Thus, this research was carried out through site observation and analysis, and selfadministered questionnaire survey. 247 questionnaire surveys were distributed to the residents of TMM and ( $\mathrm{n}=62)$ responded. When focused on the housing unit, this study provides insight on the types of outdoor spaces (front yardfront lane and backyard-back lane) and their elements and utilization, and quality of housing spaces toward users' quality of life in TMM, Kuala Lumpur. On the green open space, the assessment of the quality of life is based on three factors that are the safety level of the neighbourhood and park, health issues related to housing environment and park as well as the satisfaction on the housing amenities and park facilities. The result of this study suggests that the residents are satisfied with the existing spaces within their compound and adjacent to it and this lead towards the overall satisfaction living in the area. The quality of space and good utilisation of housing areas can lead towards a better quality of life in the Terrace housing area is confirmed.
\end{abstract}

\section{Introduction}

House quality is a major factor that can determine a comfortable environment for the users. It was stated that "housing quality can be defined as the level of satisfaction with the specific house within a chosen residential, physical and social environment, as well as its specific housing attributes" [1]. Following the weather and environmental condition, it is agreed that most of the time, users spend their time indoor [2]. These might be among the reasons that hinder users from spending their time outdoors which also affect them from socialising optimally with neighbours. Certain parts of the individual house are turned into space to park car while some are renovated to widen the indoor spaces. The rear area of the house mainly the back lane may not be seen as a potential quality space for daily activity and to a certain extent it could be neglected or perceived as negative space. Hence, properly planned space with identified activities can encourage the user to spend time outdoors.

Safety, facilities and health are known to be among the core factors that influence the life satisfaction of neighbourhood community. An open green space known as the neighbourhood park would usually equip a housing area. Neighbourhood Park can be defined as a place where diverse needs are fulfilled without the need to travel a long distance, provided necessary recreational facilities for all users and located in the middle of developments [3]. Similarly, as cited [4], neighbourhood park is defined as places that accommodate both active and passive activities, local park function and facilities to various types of users and usually serves 0.5 to 0.8 kilometre radius of catchment area [5]. A quality green open spaces or neighbourhood parks can be defined as ".... successful and excellent public green open space within a residential neighborhood area that conforms to the needs and requirements of people

1 aaniza@iium.edu.my 
including various techniques for using the space and upon agreed standards that are beyond the usual outdoor recreation and leisure expectations" [6].

Evaluating housing is necessary to improve the design and development of housing projects [7]. Hence, the concept of satisfaction has been widely used as an indicator to evaluate housing performance [8]. The residential satisfaction reflects the degree to which individuals' housing needs are fulfilled. Lack of knowledge on the residential satisfaction determinants may be contributing to the failure of many housing projects [9]. High level of satisfaction is likely to be expressed if the current housing situation follows the norms as the households judge the housing conditions based on the actual housing situation and standards [10]. Various determinants have been found to be significant to housing satisfaction ranging from housing, demographic, to socio-economic variables [11].Three main groups of determinants on neighbourhood satisfaction from the literature are categorised which are personal/household characteristics; subjective evaluations of neighbourhood attributes and subjective evaluation of the dwelling; and objective neighbourhood characteristics [12]. However, the subjective evaluations of neighbourhood attributes are deemed more important in explaining neighbourhood satisfaction than personal/household characteristics [13][14] and objective neighbourhood attributes [15][16][17]. The neighbourhood characteristics are such as public services, the general appearance of the neighbourhoods, perceived safety, and satisfaction with fellow residents [12]. Dwelling satisfaction has a significant positive impact on neighbourhood satisfaction [13][18]. On the neighbourhood characteristics, the direct effects of objective neighbourhood conditions on neighbourhood satisfaction are supported with ample evidence [12]. Living in high socioeconomic status seems to lead to greater neighbourhood satisfaction than living in poverty areas [18][14]. The positive effect is observed on neighbourhood satisfaction following clean environment and quality housing stock [19][20]. As for the personal and household characteristics, less satisfaction is seen among younger people compared to the elderly [13][14][21]. Apart from that, the presence of children seems to bring a positive effect on neighbourhood satisfaction [14] as well as social interaction in the neighbourhood [22].

Higher income and higher education level also are found to have a positive effect on neighbourhood satisfaction, and homeowners are more likely to be satisfied with their neighbourhood than renters [23]. Homeownership is said as having a profound influence on residential evaluation [24] as it provides a feeling of security and personal achievement, leading to higher selfesteem [25][26]. The housing characteristics considered in most of the empirical studies are such as structural (kitchen space, laundry and washing areas, dining area, number of bedrooms and bathrooms, etc.), locational (accessibility to central business district, local amenities, schools, etc.), and neighbourhood attributes (neighbourhood upkeep, pollution, and crime) [27][[28][14].

Therefore, this research seeks to investigate the existing housing elements such as the housing units, and the neighbourhood park, and to suggest the housing elements that can contribute to the quality of life in a neighbourhood. Hence, there are several focus which are types of outdoor spaces, utilisation and quality of outdoor spaces; and the perception of the residents on quality of life-based on the overall neighbourhood environment. On the aspect of the neighbourhood, the focus is on the level of satisfaction of the housing overall safety, which covers park and the housing environment. It is done by identifying the park facilities and housing amenities as the indicator of life satisfaction, and to study on how the green open space in housing environment contributes towards the quality of life (QOL) of the community in Taman Melati Mastika (TMM).

\section{Housing Environment and Quality of Life}

Terrace house is being considered as the densest form of landed property development. The typical lot varies such as 20 feet by 65 feet and 22 feet by 70 feet. The layout of typical terrace house can be divided into two categories: the indoor and outdoor spaces. The standard double storey terrace house indoor spaces include four bedrooms, three bathrooms, a kitchen, a dining and living space, meanwhile the outdoor spaces include the entrance area or the front yard and the back yard. The entrance is the interface between the outdoor and indoor space, between public and private space.

There are six specific modification that made the residents became dissatisfied with the indoor environment which are the extension, addition, reduction, division, removal and relocation [29]. Thus, this type of housing in Malaysia demonstrates the dynamic interaction (satisfaction/ dissatisfaction) between residents and their residential environment.

Community safety is necessary and it can be related to the connected street network that can provide a better level of surveillance and the continuous housing façade [30]. A research shows that the respondents' perception towards neighbourhood safety scored the highest [31]. However, this does not implicate that the community is considered as a safe place for them.

Safety is also an element that can influence the visitation to the park. A research shows that security is rated as the highest barrier to using in both urban parks and neighbourhood parks. The latter particularly have $65 \%$ responds agreed, and $53.8 \%$ of them are female respondents [32]. It can be understood that majority of the female user does not feel safe when spending time at the park.

The QOL is a multi-dimensional construct, consisting of material and non-material aspects of life and housing satisfaction fulfils the material dimension of QOL. The majority of researchers on QOL adopt a subjective approach to measuring citizen's satisfaction through understanding their housing aspirations and the fulfilment of actual housing needs [33]. In other words, QOL is based on the assessment of multiple needs of individuals, communities, and neighbourhood. Satisfaction with the physical features of the house tends to contribute to the overall satisfaction on the neighbourhood, which also 
affects the overall feelings positively toward life satisfaction and well-being. The quality of the houses in the urban area is highly concerned with the improvements in living conditions which also relate to the health improvement of the urbanites while upgrading the standard of living [34].

\section{Methodology}

TMM (figure 1) which is located in Setapak, Kuala Lumpur, a double-storey terrace housing area was selected as the case study. This area can be considered as matured with various facilities such as schools, commercial areas, mosque, green open spaces, and the light rail transit (LRT) also covers this area with a designated station named as Taman Melati station.

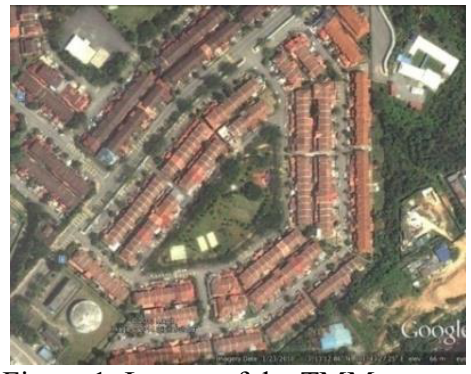

Figure 1: Layout of the TMM

As mentioned earlier, there is two main focus of this study which is reflected in the methodology of the data collection, where it starts with the housing units, followed by the neighbourhood park. Observation and survey questionnaire have been identified as the primary technique to collect the data.

For the site observation, the layout of the TMM was developed by refining the layout from the Google Map using the AutoCAD software. Observations were done to identify spaces within TMM, types of houses (intermediate, corner lot, and end lot), type of extensions, hardscape and softscape elements of spaces identified, shared back lane, and observation on the neighbourhood park particularly on the facilities and amenities. The observation was conducted for three days from 15th of March of 2014 until 17th March 2014. Observation data collected earlier was used to support the development of the questionnaire.

The questionnaire was prepared with four sections respondent's profile, quality of spaces at the individual unit, quality of green open spaces, and quality of life-based on spaces within TMM. The survey questionnaire survey was developed as a semi-structured and self-administered questionnaire. A pilot study to test the survey questionnaire was done in TMM. Six respondents were involved and following their feedback; minor changes was done. There were 250 units with four units were under major construction. Hence, 246 copies of survey questionnaire were prepared and were coded accordingly (figure 2) to roughly identify the unit's location. These units are grouped based on their road number and the shared back lane. The survey questionnaire was delivered to every house through the mailbox and the residents of TMM were asked to return the survey questionnaire in a box located at the TMM guardhouse. The period of the survey was from 15th of March 2014 until 29th of March 2014. The data from the survey questionnaire was analysed using the Statistical Package for Social Science (SPSS) software.

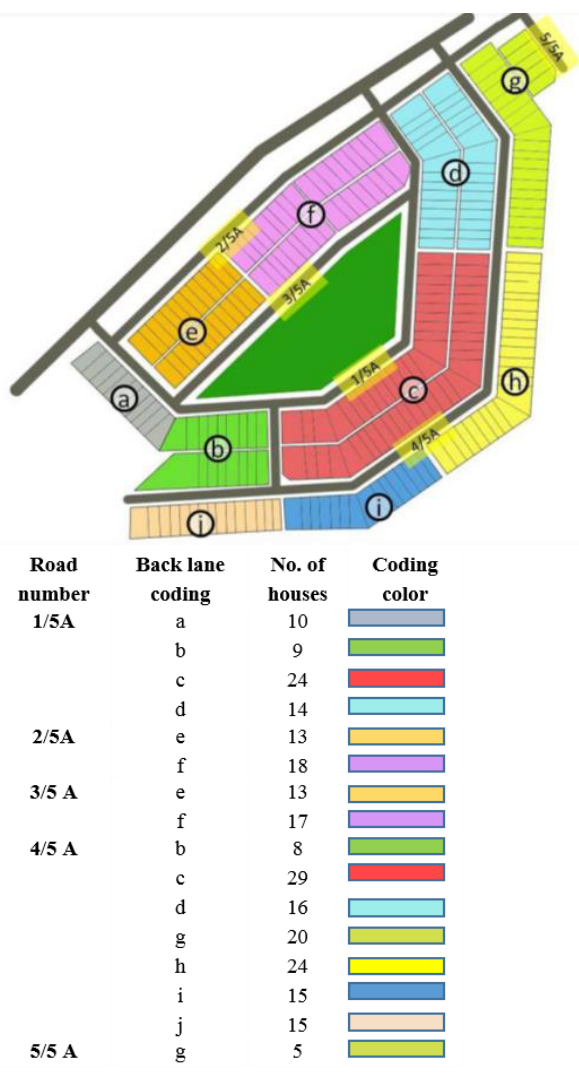

Figure 2: The back lane coding according to housing layout

\section{Analysis and Findings}

The strategy of analysis and its presentation are done according to two main areas, which starts with outdoor space provision, followed by the analysis of the neighbourhood park. As mentioned before, the analysis evaluates the existing housing elements such as the housing units, and the neighbourhood park, and to suggest the housing elements that can contribute to the quality of life in a neighbourhood.

\subsection{Analysis on Outdoor Spaces of TMM}

The strategy or flow in analysing the data for the observation and survey questionnaire is shown in figure 3 .

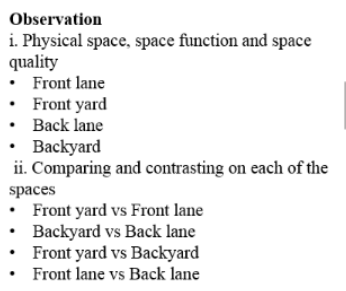

Survey Questionnaire Demography profile of TMM i. Space utilizindoor - Indoor iii. Resident level of satisfaction on spaces and quality life

Figure 3: The strategy of data analysis for outdoor space provision 
The housing units in TMM can be divided into three types which are intermediate, corner lot and end lot (figure 4).

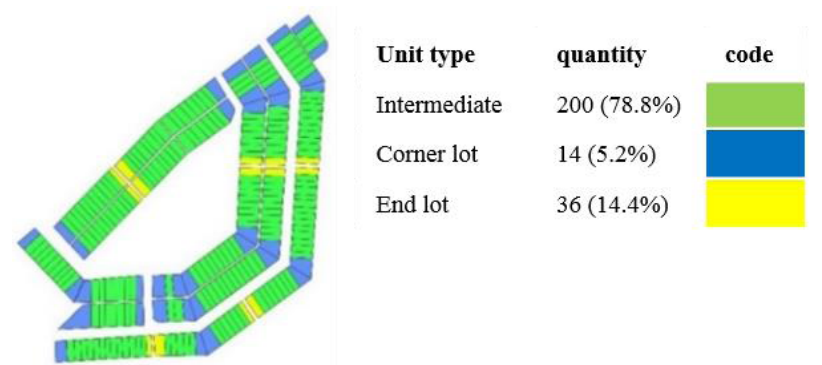

Figure 4: Unit types - location and quantity

There are five front roads/lanes exist in TMM (figure 5). The width of this road is $8 \mathrm{~m}$.

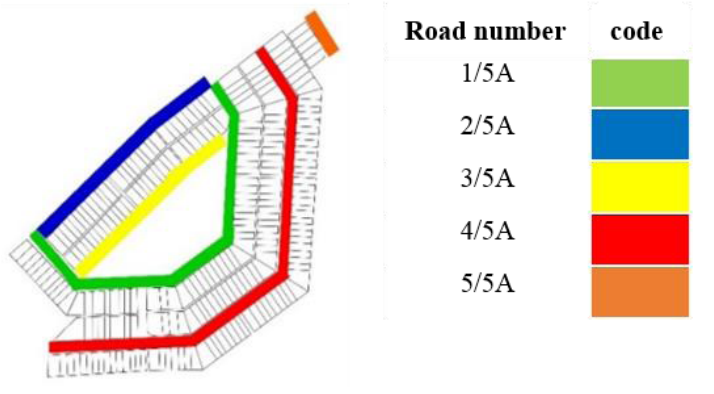

Figure 5: Layout of the front roads/lanes

\subsubsection{Front yard and space quality}

For the purpose of analysis, the front yard can be categorised into four types which are fully extended $(100 \%)$, without green area, with green area, and original design/layout - refer images in figure 6 .
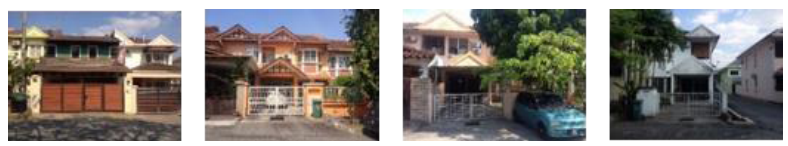

Figure 6: Types of front yard - from fully extended to original design (from left to right)

For the $100 \%$ extended and without green space, it involves indoor space being extended, be it the ground floor or first floor. The ground level spaces are usually turned into semioutdoor space and used as car porch. The second category of house extension (without green space) does not involve indoor space extension. However, the porch area is being widened until the front gate. This spaces also seem to be turned into car porch. The third category is where the house is being extended (involving the porch area only - without indoor spaces being extended) and with green space. The first two categories have totally eliminated the green space. When these categories are further collapsed into extended and non-extended, it can be seen that $85.4 \%$ are extended, with only $9.8 \%$ of green space (figure 7 ). Hence, it can be said that for the front yard, once extended, the chances to have landscape/green space integrated with the extension is small.
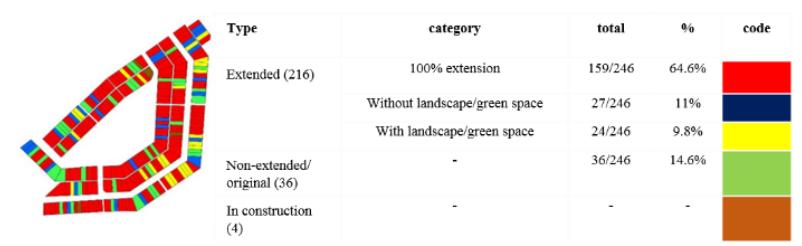

Figure 7: Analysis of extended and non-extended units with and without green space

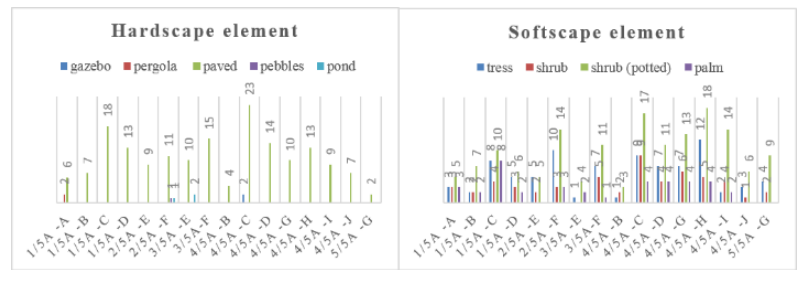

Figure 8: Hardscape element (left) and softscape element (right) in front yard area

The analysis is continued on observed units with landscape/green spaces. The result is presented in figure 8 where the location of the units is indicated by the road number and back lane codes. In general, it can be concluded that that most of the house with landscape/green spaces have more softscape element rather than hardscape element. The front yard with the best space quality is the space that has a balance between hardscape and softscape element with the later having higher quantity. For houses that are fully extended and without green space, the residents tend to make use by having potted plants as an alternative to having greens.

The back lane is shared among the row of houses and it can be characterised into two. Type 1 (top) is where it is shared by two rows of houses (indicated in colours), and type 2 (bottom) is where it is shared by only a row of houses (figure 9 . These back-lanes are enclosed where only residents of these row of houses can access it from their backyard or kitchen area.

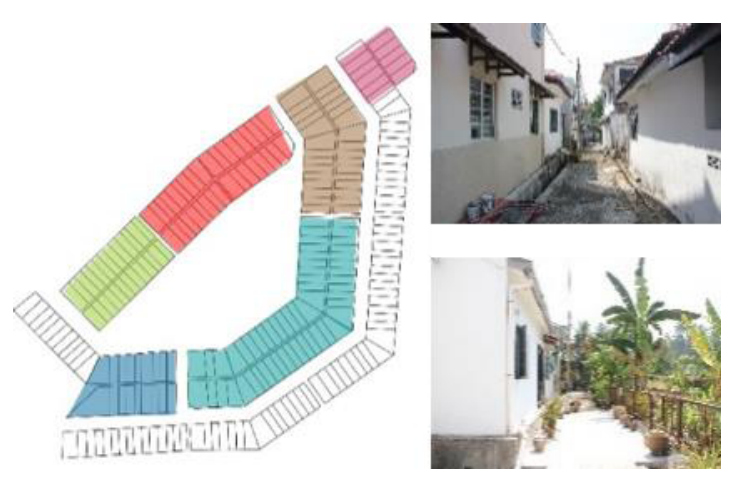

Figure 9: Type of backlanes

\subsubsection{Backyard and space quality}

The backyard can also be categorised into four types which are type $1-100 \%$ extension (turned into indoor spaces); type 2 - more than $50 \%$ of the backyard turned into indoor spaces with some outdoor spaces; type 3 - with less than 
$50 \%$ indoor space extension and with outdoor spaces; and type 4 - the backyard's original design is maintained with the outdoor space functions as drying and storing area (figure 10).

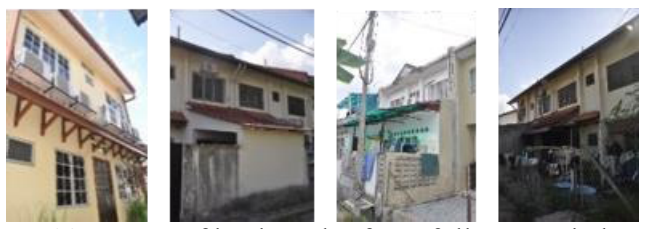

Figure 10: Types of backyard - from fully extended to the original design (left to right)

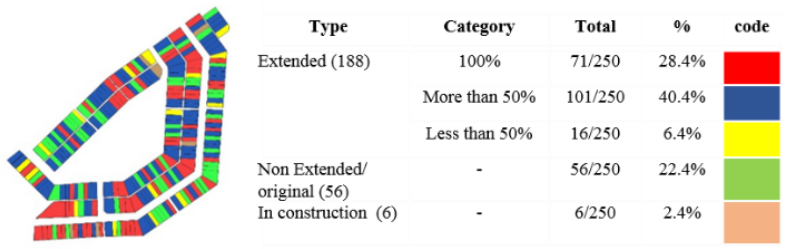

Figure 11: Analysis on extended and non-extended backyards

Figure 11 shows the highest percentage of extension of the house in the backyard area that they extend their backyard area more than $50 \%$ of the area is $64.6 \%$. On the other hands, the lowest percentage of extension of the house is $6.4 \%$ that they extend less than $50 \%$ of the area. House with the original layout at the backyard is $22.4 \%$.

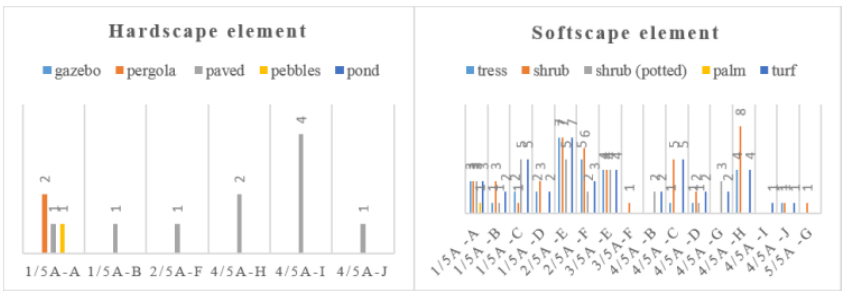

Figure 12: Hardscape element and softscape element at the backyard

Figure 12 shows the hardspace element and softscape element in each of the house according to back lane coding. It shows that most of the houses have more softscape element rather than hardscape element. The back yard with the best space quality is the space that has a softscape element that makes the backyard livelier.

\subsubsection{Comparing the utilisation of outdoor spaces}

There are three types of extension among the front yards. Most of the extensions in the front yard are turned into car porch. It is also becoming another space such as playing area, gardening area (the ones with landscape area extension) and drying area. Meanwhile, the front lane is utilised for vehicle access, which is becoming a second car park for the user.

There are three types of extension among the back yards. Space is limited due to the extension. Meanwhile, there are two types of the back lane, which has minimal activities. In comparison, the front yard has more activities than back yard area. The extensions of the front yards were mostly bigger than back yards. Front yard also serves as the entrance transition before entering the house. Meanwhile, the backyard has fewer activities and most of them were extended and turned into an indoor space. The front lane has more activities than the back lane area. The front lane is functioning as the main road in TMM and it is the access to each of the road. The back lane has less activity due to low utilisation and some being shared lane.

\subsection{Analysis of Survey Questionnaire}

\subsubsection{Demography Profile of TMM}

A total of 62 self-administered questionnaires were returned. At the response rate of $25.3 \%$, the adequacy of the sample size was calculated and it is significant at $11 \%$ confidence interval [35]. Table 1 shows the demographic details of the respondents. $53.2 \%$ of the respondents were males, $45.2 \%$ were females and $1.6 \%$ of the overall respondents did not state his/her gender. Regarding ethnicity, Malays represent the largest percentage which is $75.8 \%$. The rest of the respondents $(11.3 \%, 4.8 \%, 4.8 \%$ and $3.2 \%$ ) is represented by Chinese, Indian, Sikh and other races respectively. $43.5 \%$ of the respondents aged between $50-59,17.7 \%$ aged $30-39,16.1 \%$ aged from $40-49,16.1 \%$ were $60-69$ years old and the rest of the respondent $(4.8 \%$ and 1.6\%) aged between 20-29 and 70 and above respectively.

\subsubsection{Space Utilisation: front lane, front yard, back lane, and backyard}

Table 1 shows the residents' time spent in outdoor spaces on weekdays and weekend in TMM. It can be said that in the morning during weekdays, most users spent less than 1 hour in the front area (front lane \& front yard) than back area. About $75.8 \%$ user spent less than one hour in front lane area in the morning, same as in the evening. Meanwhile, in the backyard area, 69.4\% user spent time less than one hour in the back lane area. In the evening, $62.9 \%$ users spent time at the back lane. However, during the weekend, most users spend less than one hour in the front and back area. In the morning, 66.1\% users spent less than one hour in the front lane area, meanwhile in the evening, $72.6 \%$ users spent their time in the front lane. At the back area, $62.9 \%$ users spent less than one hour in the morning and evening, $61.3 \%$ user spent less than one hour in the same spot. It can be said that the residents spend more time in the front area than the back area.

The duration of time spent in the front yard is longer as compared to the weekdays (Table 1). Similarly, more residents spent longer hours in the back yard during the weekends as compared to the weekdays. It has shown that front yard and back yard has been utilized more than just entering the house. They are also used for weekend activities, which justified the significant of front yard and back yard to the housing design elements. 
Table 1: Usage of outdoor spaces during weekend and weekdays

\begin{tabular}{|c|c|c|c|c|c|c|c|c|c|c|c|}
\hline \multicolumn{12}{|c|}{ WEEKEND } \\
\hline \multirow[t]{2}{*}{ Duration } & \multicolumn{2}{|c|}{ Less than 1 hour } & \multicolumn{2}{|c|}{$1-2$ hour } & \multicolumn{2}{|c|}{$2-3$ hour } & \multicolumn{2}{|c|}{ More than 3 hour } & \multicolumn{2}{|c|}{ No respond } & TOTAL \\
\hline & $\begin{array}{l}7 \mathrm{am}- \\
7 \mathrm{pm}\end{array}$ & $\begin{array}{l}7 \mathrm{pm}- \\
7 \mathrm{am}\end{array}$ & $\begin{array}{l}7 \mathrm{am}- \\
7 \mathrm{pm}\end{array}$ & $\begin{array}{l}7 \mathrm{pm}- \\
7 \mathrm{am}\end{array}$ & $\begin{array}{l}7 \mathrm{am}- \\
7 \mathrm{pm}\end{array}$ & $\begin{array}{l}7 \mathrm{pm}- \\
7 \mathrm{am}\end{array}$ & $\begin{array}{l}7 \mathrm{am}- \\
7 \mathrm{pm}\end{array}$ & $\begin{array}{l}7 \mathrm{pm}- \\
7 \mathrm{am}\end{array}$ & $\begin{array}{l}7 \mathrm{am}- \\
7 \mathrm{pm}\end{array}$ & $\begin{array}{l}7 \mathrm{pm}- \\
7 \mathrm{am}\end{array}$ & \\
\hline \multirow{3}{*}{$\begin{array}{l}\text { Front } \\
\text { yard// } \\
\text { Porch }\end{array}$} & 32 & 43 & 21 & 12 & 3 & 2 & 6 & 2 & - & 3 & 62 \\
\hline & $(\%)$ & $(\%)$ & $(\%)$ & $(\%)$ & $(\%)$ & $(\%)$ & $(\%)$ & $(\%)$ & $(\%)$ & $(\%)$ & $(\%)$ \\
\hline & 51.6 & 69.4 & 33.9 & 19.4 & 4.8 & 3.2 & 9.7 & 3.2 & - & 4.8 & 100 \\
\hline \multirow[t]{3}{*}{ Front lane } & 41 & 45 & 11 & 6 & 2 & 1 & 5 & 3 & 3 & 7 & 62 \\
\hline & $(\%)$ & $(\%)$ & $(\%)$ & $(\%)$ & (\%) & $(\%)$ & $(\%)$ & $(\%)$ & (\%) & (\%) & (\%) \\
\hline & 66.1 & 72.6 & 17.7 & 9.7 & 3.2 & 1.6 & 8.1 & 4.8 & 4.8 & 11.3 & 100 \\
\hline \multirow{3}{*}{ Back yard } & 23 & 30 & 14 & 6 & 3 & 4 & 1 & - & 21 & 22 & 62 \\
\hline & $(\%)$ & $(\%)$ & $(\%)$ & $(\%)$ & $(\%)$ & $(\%)$ & $(\%)$ & $(\%)$ & $(\%)$ & $(\%)$ & $(\%)$ \\
\hline & 37.1 & 48.4 & 22.7 & 9.7 & 4.8 & 6.5 & 1.6 & - & 33.9 & 35.5 & 100 \\
\hline \multirow[t]{3}{*}{ Back lane } & 39 & 38 & 7 & 3 & 1 & 1 & - & - & 15 & 20 & 62 \\
\hline & $(\%)$ & $(\%)$ & $(\%)$ & $(\%)$ & $(\%)$ & $(\%)$ & $(\%)$ & $(\%)$ & $(\%)$ & $(\%)$ & $(\%)$ \\
\hline & 62.9 & 61.3 & 11.3 & 4.8 & 1.6 & 1.6 & - & - & 24.2 & 32.3 & 100 \\
\hline \multicolumn{12}{|c|}{ WEEKDAYS } \\
\hline Duration & \multicolumn{2}{|c|}{ Less than 1 hour } & \multicolumn{2}{|c|}{ 1-2 hour } & \multicolumn{2}{|c|}{$2-3$ hour } & \multicolumn{2}{|c|}{ More than 3 hour } & \multicolumn{2}{|c|}{ No respond } & TOTAL \\
\hline & $\begin{array}{l}7 \mathrm{am}- \\
7 \mathrm{pm}\end{array}$ & $\begin{array}{l}7 \mathrm{pm}- \\
7 \mathrm{am} \\
\end{array}$ & $\begin{array}{l}7 \mathrm{am}- \\
7 \mathrm{pm}\end{array}$ & $\begin{array}{l}7 \mathrm{pm}- \\
7 \mathrm{am}\end{array}$ & $\begin{array}{l}\text { 7am- } \\
7 \mathrm{pm}\end{array}$ & $\begin{array}{l}7 \mathrm{pm}- \\
7 \mathrm{am}\end{array}$ & $\begin{array}{l}7 \mathrm{am}- \\
7 \mathrm{pm}\end{array}$ & $\begin{array}{l}7 \mathrm{pm}- \\
7 \mathrm{am}\end{array}$ & $\begin{array}{l}7 \mathrm{am}- \\
7 \mathrm{pm}\end{array}$ & $\begin{array}{l}7 \mathrm{pm}- \\
7 \mathrm{am} \\
\end{array}$ & \\
\hline \multirow{3}{*}{$\begin{array}{l}\text { Front } \\
\text { yard/ } \\
\text { Porch }\end{array}$} & 46 & 46 & 7 & 8 & 5 & 3 & 3 & 3 & 1 & 2 & 62 \\
\hline & $(\%)$ & $(\%)$ & $(\%)$ & $(\%)$ & $(\%)$ & $(\%)$ & $(\%)$ & $(\%)$ & $(\%)$ & $(\%)$ & $(\%)$ \\
\hline & 74.2 & 74.2 & 11.3 & 12.9 & 8.1 & 4.8 & 4.8 & 3.2 & 1.6 & 3.2 & 100 \\
\hline \multirow[t]{3}{*}{ Front lane } & 47 & 47 & 6 & 4 & 2 & 1 & 3 & 3 & 4 & 7 & 62 \\
\hline & $(\%)$ & $(\%)$ & $(\%)$ & $(\%)$ & $(\%)$ & $(\%)$ & $(\%)$ & $(\%)$ & $(\%)$ & (\%) & $(\%)$ \\
\hline & 75.8 & 75.8 & 9.7 & 6.5 & 3.2 & 1.6 & 4.8 & 4.8 & 6.5 & 11.3 & 100 \\
\hline \multirow[t]{3}{*}{ Back yard } & 30 & 31 & 6 & 5 & 4 & 3 & 1 & - & 21 & 23 & 62 \\
\hline & (\%) & (\%) & $(\%)$ & $(\%)$ & $\begin{array}{l}\%) \\
\end{array}$ & $(\%)$ & $(\%)$ & (\%) & (\%) & $(\%)$ & (\%) \\
\hline & \begin{tabular}{|l|l|}
48.4 \\
\end{tabular} & \begin{tabular}{|l|}
50.0 \\
\end{tabular} & 9.7 & 8.1 & 6.5 & 4.8 & 1.6 & - & 33.9 & 37.1 & 100 \\
\hline \multirow[t]{3}{*}{ Back lane } & 43 & 39 & 2 & 2 & 1 & 1 & - & - & 16 & 20 & 62 \\
\hline & $(\%)$ & $(\%)$ & $(\%)$ & $(\%)$ & $(\%)$ & $(\%)$ & (\%) & $(\%)$ & $(\%)$ & $(\%)$ & $(\%)$ \\
\hline & 69.4 & 62.9 & 3.2 & 3.2 & 1.6 & 1.6 & - & - & 25.8 & 32.3 & 100 \\
\hline
\end{tabular}

\subsubsection{Residents Level of Satisfaction and Quality of Life in TMM}

This section presents the level of satisfaction towards living condition and the quality of life in TMM. Referring to figure 14 , the perceived level of satisfaction towards their living place as shown in figure 13, shows that majority $(80 \%)$ of the respondents were satisfied and very jubilant compared to only $13 \%$ that was dissatisfied. As for the perceived quality of life, $77 \%$ were satisfied while $13 \%$ were dissatisfied.

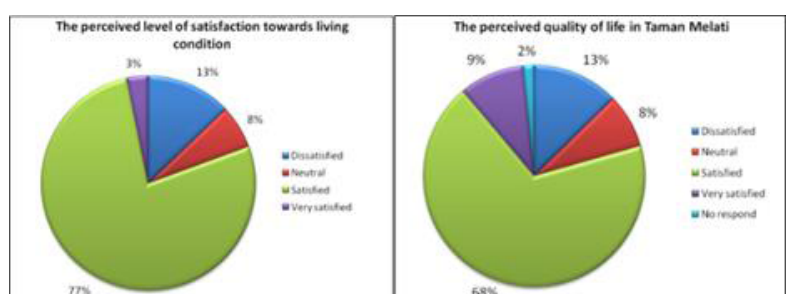

Figure 13: The perceived level of satisfaction towards living condition (left) and the perceived quality of life in TMM (right)
Factors of satisfaction can be related and further discussed as follows:

(a) Housing unit design of outdoor spaces - front yard and back yard.

The study analyses on the location of the front yard and back yard and its influence on the respondents' satisfaction towards living condition and quality of life. Referring to figure 2, there are three types of housing front yards, which are facing the park, the neighbour's front yard and the road. Meanwhile, there are two kinds of housing backyard, which are facing the neighbour's back yard separated by the back lane, and back yard facing the back road. Figure 14 shows the influence of these types of front yard and back yard towards satisfaction on living and quality of life in TMM. Among the respondents living in housing with front yard facing the park, 94\% are satisfied with their living condition and $100 \%$ perceived the quality of life in TMM. Therefore, it can be said that the park and distance from the house to the park plays a significant role in providing satisfactory living condition and QOL. 


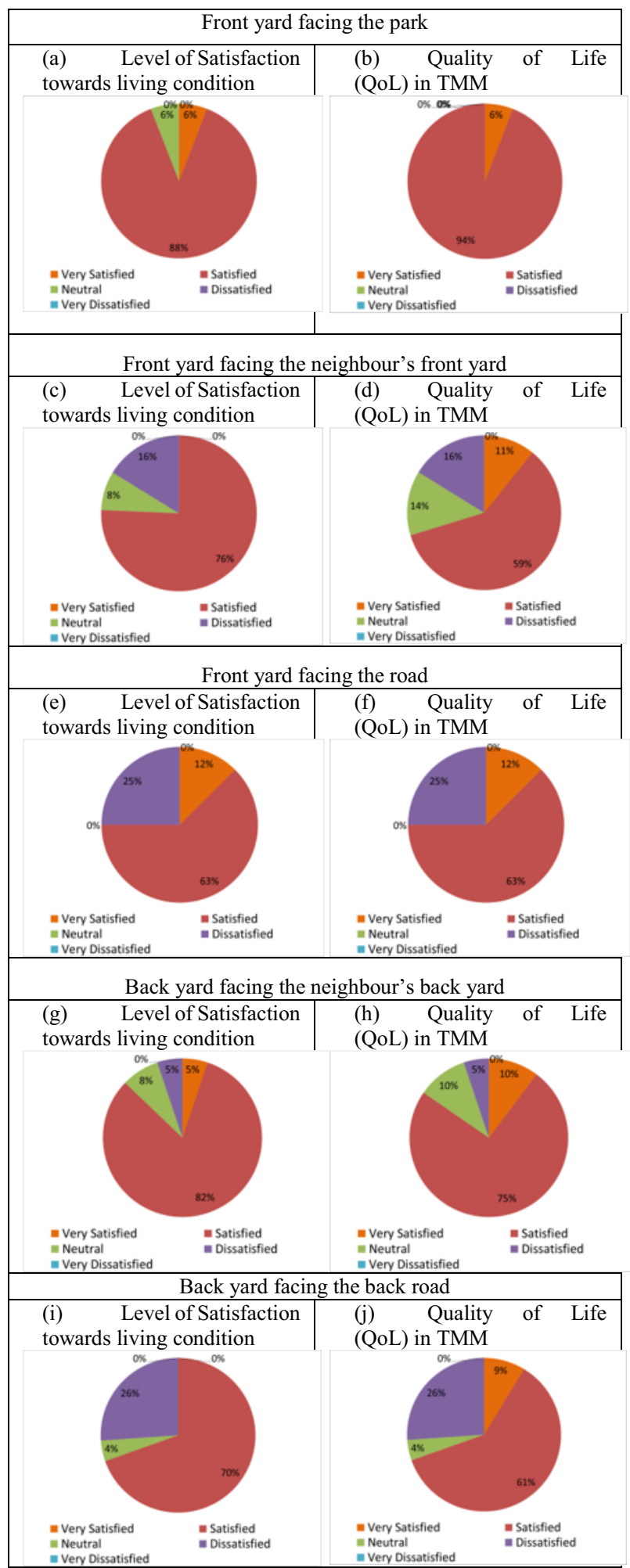

Figure 14: The types of front and back yard which influence on the respondents' level of satisfaction towards living condition (left) and the quality of life in TMM (right)

\section{(b) Safety in the housing environment and park}

Perception on safety level of TMM housing environment was measured using the 5-point Likert Scale. Figure 15 shows the respondents' perception of security level in TMM housing environment. The majority of the respondent agreed to the statement "There is no noise disturbance occurs in this neighbourhood" with high agreement $(41.9 \%)$ followed by $33.9 \%$ agreement on the statement of "you feel secure living in your neighbourhood area".

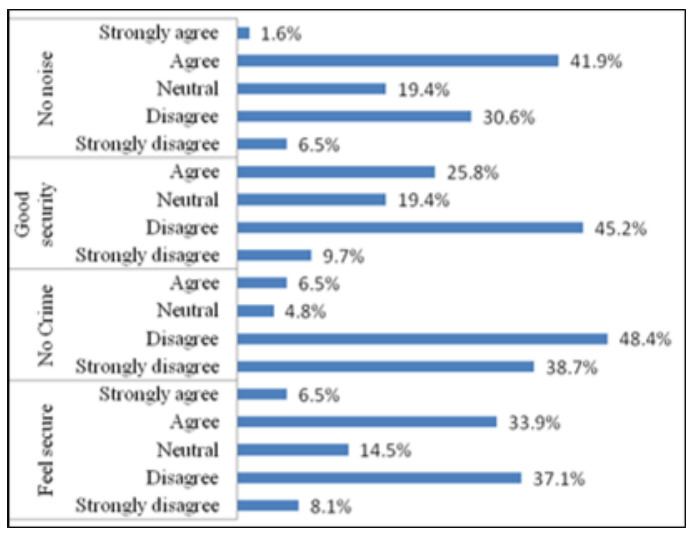

Figure 15: Perception of safety level of TMM housing environment

Those statements would indicate the degree of security of their residence. However, $48.4 \%$ disagreed with the neighbourhood having no crime recorded, followed by $45.2 \%$ disagreement with the neighbourhood having proper security measures.
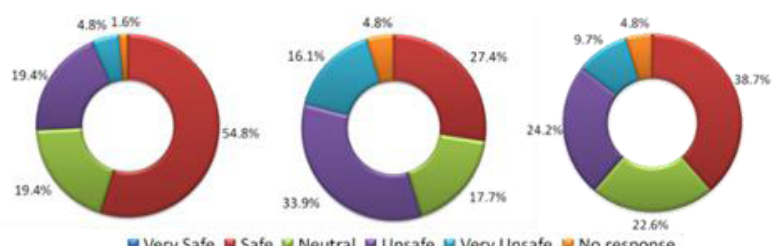

Figure 16: Percentage of safety level at the park during the day (left), night (middle) and overall safety level (right)

Safety level at the park was assessed from the respondent perception in which they rated the security level from $1=$ Very Safe until $5=$ Very Unsafe for 3 cases which are safety during the day, during the night and overall safety level. The results in figure 16 show that $54.8 \%$ of the respondents perceived the park as safe during the day. As for the safety during the night, the majority $(33.9 \%)$ rated the park as unsafe. The overall safety level was perceived as safe $38.7 \%$. The security level at the park was also assessed from the witnessed illegal activities and existence of possible hiding spots in the park. Both questions require the respondent to identify the zone in which they had seen the crime as well as the potential hiding place. The areas and their descriptions are shown in figure 17.
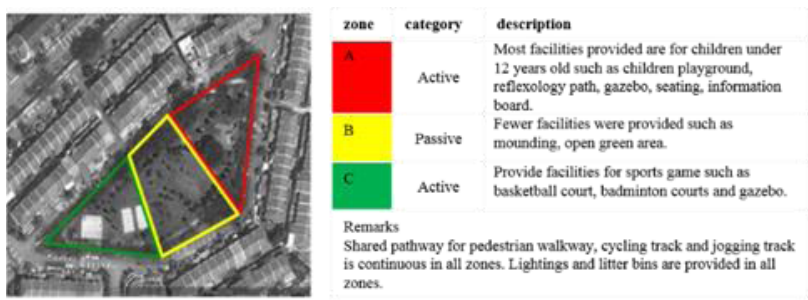

Figure 17: Identified zones of the neighbourhood park 
$64.5 \%$ of the respondents stated that they had witnessed illegal activities in the park compared to $33.9 \%$ that never observed any illegal activities as shown in figure 17. For those who had seen the crime, the majority of them said that it happened mostly in Zone A $(38.7 \%)$ while the least is Zone B (1.6\%) (figure 17). However, the data shown does not show the actual point or place of the witnessed illegal acts. The criminal activities identified are such as theft and immoral acts by teenagers as commented by the respondents in the questionnaire. They also mentioned that those teenagers are from the adjacent neighbourhood. This situation may have happened due to lack of supervision from the security personnel and the easy entry into the neighbourhood.

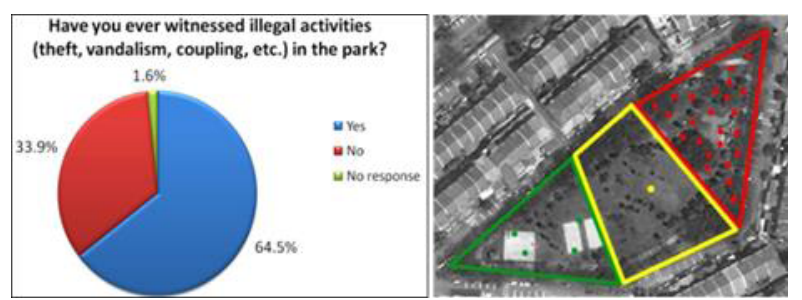

Figure 18: Illegal activities - respondents' feedback (left) and zones involved (right).

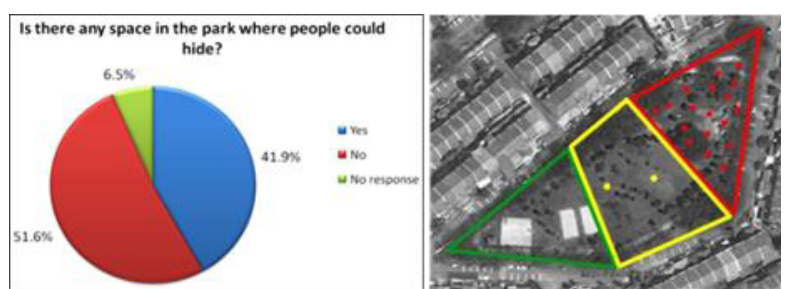

Figure 19: Possible hiding spots at the park - respondents' feedback (left) and zones involved (right)

Referring to figure $19,51.6 \%$ of the respondents stated that there is no possible hiding spot in the park, while $41.9 \%$ answered the opposite while indicating the zones involved with the highest possible hiding place is Zone A (29\%). However, the data only show the frequency of the potential hiding spots and not the exact hiding location. Zone A seems to have the most hiding spots may be due to the availability of the children play structure with enclosed parts and the density of vegetation in the area. Some trees planted might seem to create potential hiding spots between its trunks. Dim lightings in the park may add to the possibility of Zone A to have possible hiding spots.

(c) Sufficiency of facilities provided and its current condition

The park's quality was assessed based on the residents' satisfaction with the present state of the park facilities and the sufficiency of the facilities. The result show that the majority $(53.2 \%)$ of the respondents were satisfied with the sufficiency of the park facilities provided compared to only $25.8 \%$ were unsatisfied (figure 20). Similar figures were also shown to their satisfaction towards the condition of the facilities provided where $51.6 \%$ were satisfied, while $22.6 \%$ were dissatisfied (figure 21 ).

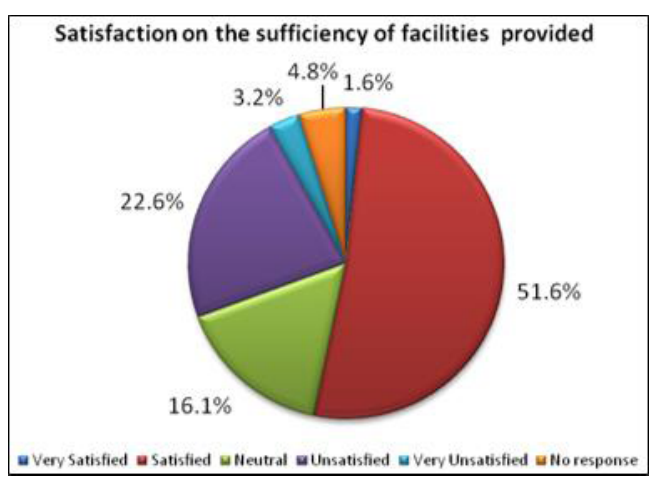

Figure 20: Satisfaction with the sufficiency of facilities provided

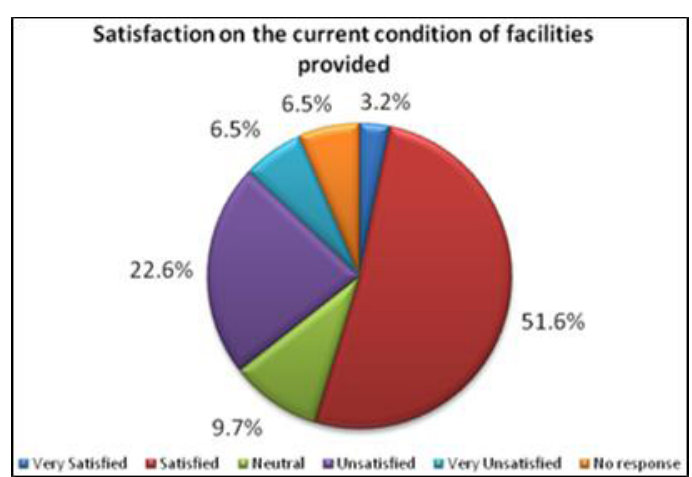

Figure 21: Satisfaction on the current condition of facilities provided

However, some of the facilities are in poor conditions (figure 22) with much-broken seating, uncovered drain holes, uneven or cracked pathway, broken lamp, broken litter bins, broken playing equipment, and immoral scribbling on the play equipment. However, due to the majority of the respondents were satisfied (figure 21), it can be said that the park still functions as recreational and leisure space despite its poor conditions at its facilities.

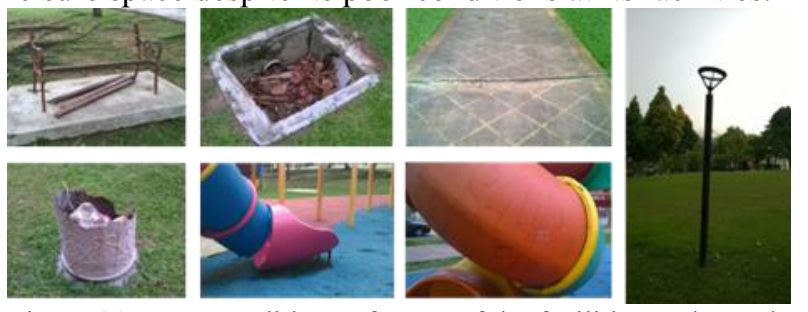

Figure 22: Poor conditions of some of the facilities at the park

\section{(d) Sufficient roadside parking and road condition}

In addition to the above, the following discussion is on the facilities and amenities of TMM. The facilities that were assessed in this research were the sufficiency of parking bays and quality of the road. It can be understood from figure 23 that $38.7 \%$ of the resident respondents agreed to both sufficient parking provided and excellent road quality while $48.4 \%$ thinks there is insufficient parking space. $35.4 \%$ of the residents do not feel the road quality is good. 


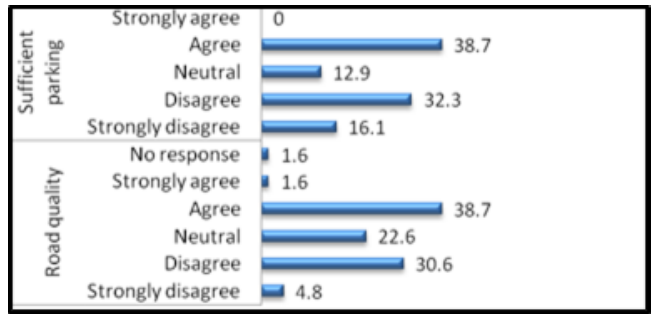

Figure 23: Satisfaction with the current condition of parking and road quality

\section{Conclusion}

The first objective is to record existing housing elements such as the homes and neighbourhood context. In the context of space provision, many homes are being extended, and this is very commonly done in the terrace housing area which involved turning the front yard into paved and roofed surfaces which serve as car porch among other, leading to smaller amount of landscape/green spaces. Hence, it can be suggested that more built area are seen, and this could lead towards imbalance environment. The urban area is known for its limitation of green space. The needs to extend the indoor spaces or to renovate the exterior spaces to become semi-outdoor space can make the situation worse. The back lane is seen as a commonly ignored/neglected area. However, in TMM the type 2 back lane seems to be a useful place due to a lot of ongoing activities such as gardening. Type one back lane on another hand, is currently abandoned by some residents due to the small amount of space to do activities.

The second objective is to suggest the housing elements that can contribute to the quality of life in a neighbourhood. The results have shown that respondents living in homes where their front yards are facing the neighbourhood park have the very high satisfaction to their living condition. Therefore, the relationship of the front yard with the neighbourhood park is the best design element that can be suggested for a neighbourhood towards the QOL. In addition to that, security of a neighbourhood is also crucial. Furthermore, the sufficiency of facilities is also critical. These facilities need to be maintained in a good condition to avoid further vandalism or wrong hiding spots. Lastly but never the least, another important element would be the sufficient of roadside parking and the road quality. With consideration of these elements, the QOL of TMM can be improved.

\section{References}

1. Lazenby, K.,(1988).Occupancies satisfaction in the white house sector in the municipality of Bloemfontein: A study of process patterns and strategy. Bloemfontein: University of the Orange Free State.

2. Abu Bakar. A., (2007), User response to thermal comfort of outdoor urban spaces in hot-humid region, Ph.D. thesis, University of Nottingham, United Kingdom.

3. Chapman, G. A. (1999). Design Variables and the Success of Outdoor Neighbourhood Recreational
Facilities. Unpublished Master Thesis, The University of Arizona, Arizona.

4. Nurhayati A. M., \& Manohar M. (2010). Developing Quality Neighbourhood Parks: A Malaysian Experience. Proceedings of the Healthy Parks Healthy People: International Congress 2010. Organised by Parks Victoria; IUCN; Beyond Blue; Deakin University; Director of National Parks, Australian Government; and World Tourism Organization (UNWTO) held in Melbourne Convention Centre, Melbourne.

5. Von Kursell, A. A. (1997). Replanning Urban Parks. Unpublished Masters of Urban and Rural Planning Thesis, Technical University of Nova Scotia, Halifax, Nova Scotia, Canada.

6. Nurhayati Abdul Malek, Manohar Mariapan, \& Mustafa Kamal MohdShariff (2012), The Making of a Quality Neighbourhood Park: A Path Model Approach. Procedia Social and Behavioral Sciences, SciVerse Science Direct, 49, 202-214.

7. Preiser, W.F.E., (1989), Towards a performance-based conceptual framework of systematic POES, in W.F.E. Preiser (ed), Building Evaluation, New York: Plenum Press.

8. Paris, D.E., and Kangari, R., (2005), Multifamily Affordable Housing: residential satisfaction, Journal of Performance and Constructed Facilities, Vol. 19, pp. 138-145.

9. Salleh, A.G., (2008), Neighbourhood factors in private low-cost housing in Malaysia, Habitat International, Vol. 32, pp. 485-493.

10. Ogu, V.I., (2002), Urban residential satisfaction and the planning implications in a developing world context: the example of Benin City, Nigeria, International Planning Studies, Vol. 7, pp. 37-53.

11. Tan, T.H., (2012), Housing satisfaction in medium-and high-cost housing: the case of Greater Kuala Lumpur, Malaysia, Habitat International, Vol. 36, pp. 108-116.

12. Permentier, M., Bolt, G., and van Ham, M., (2011), Determinants of neighbourhood satisfaction and perception of neighbourhood reputation, Urban Studies, Vol. 48 (5), pp. 977-996

13. Lu, M., (1999), Do people move when they say they will? Inconsistencies in individual migration behaviour, Population and Environment, Vol. 20, pp. 467-488.

14. Parkes, A., Kearns, A., and Atkinson, R., (2002), What makes people dissatisfied with their neighbourhoods? Urban Studies, Vol. 39 (13), pp. 2413-2439.

15. Campbell, A., Converse, P.E., and Rodgers, W. L., (1976), The quality of American life: perceptions, evaluation and satisfactions, New York: Russell Sage.

16. Carp, F., Zawadski, R., and Shokron, H., (1976), Dimensions of urban environmental quality, Environment and Behavior, Vol. 8, pp. 239-265.

17. Galster, G., (1987), Homeowners and neighbourhood reinvestment, Durham, NC: Duke University Press.

18. Mohan, J., and Twigg, L., (2007), Sense of place, quality of life and local socioeconomic context: evidence from the survey of English housing, 2002/03, Urban Studies, Vol. 44, pp. 2029-2045. 
19. St John, C., and Bates, N.A., (1990), Racial composition and neighbourhood evaluation, Social Science Research, Vol. 19, pp. 47-61.

20. Basolo, V., and Strong, D., (2002), Understanding the neighbourhood: from residents' perceptions and needs to action, Housing Policy Debate, Vol. 13, pp. 83-105

21. Chapman, D.W. and Lombard, J.R., (2006), Determinants of neighbourhood satisfaction in fee-based gated and non-gated communities, Urban Affairs Review, Vol. 41, pp. 769-799.

22. Dekker, K. and Bolt, G., (2005), Social cohesion in postwar estates in the Netherlands: differences between social-economic and ethnic groups, Urban Studies, Vol. 42, pp. 2447-2470.

23. Harris, D., (2001), Why are whites and blacks averse to black neighbours?, Social Science Research, Vol. 30, pp. 100-116

24. Barcus, H.R., (2004), Urban-rural migration in the USA: an analysis of residential satisfaction, Regional Studies, Vol. 38 (6), pp. 643-657.

25. Rohe, W.M., and Stegman, M.A., (1994), The effects of home ownerships on the self-esteem, perceived control and life satisfaction of low-income people, Journal of the American Planning Association, Vol. 60 (2), pp. 173184.

26. Rohe, W.M., Van Zandt, S., and McCarthy, G., (2001), The social benefits and cost of homeownership: a critical assessment of research, low-income homeownership. Working paper series, Joint Centre for Housing Studies, Harvard University.

27. Baum, S., Arthurson, k., and Rickson, K., (2010), Happy people in mixed-up places: the association between the degree and type of local socioeconomic mix and expressions of neighbourhood satisfaction, Urban Studies, Vol. 47, pp. 467-485

28. Hipp, J., (2010), What is the 'neighborhood' in neighbourhood satisfaction? Comparing the effects of structural characteristics measured at the microneighborhood and trace levels, Urban Studies, Vol. 47, pp. $2517-2536$

29. Erdayu, O. O., Esmawee, E., and Masran, S., (2010). Adapting By Altering: Spatial Modifications of Terraced Houses in the Klang Valley Area, Asian Journal of Environment-Behaviour Studies, Vol.1, No.9, pp.1-10.

30. City and County of Swansea (2014). Places to live: Residential, Design Guideline.

31. Yahaya. N., Sabri, B., Abdullah, S.F.Z., Abdullah, S.S., Momtaz, Y.A., and Hamid, T.A., (2012) Impact on Housing Environment and Neighbourhood Safety Towards Perceived Quality of Life Among Older Persons, Indian Journal of Geontology, Vol. 26, No. 1, pp. 227-241

32. Heather E. Wright Wendela, Rebecca K. Zarger, James R. Mihelcic (2012). Accessibility and Usability: Green Space Preferences, Perceptions, and Barriers in a Rapidly Urbanizing City in Latin America, Landscape and Urban Planning 107, pp. 272-282

33. Hikmat, A. M. F., and Al-Betawi, Y.,(2009). Quality of Life in Cities Setting up Criteria for Amman-Jordan, Social Indicator Research Series, 93: 407-432.
34. Glatzer, W., Camfield, L.Møller, V. and Rojas, M (2015), Exploration of well-being of nations and continents, Global Handbook of Quality of Life, Springer, Social Science, pp. 704-705

35. www.surveysystem.com/sscale.htm, [10 February 2016] 